\title{
Phenotypic and genetic relationships of common health disorders with milk and fat yield persistencies from producer-recorded health data and test-day yields
}

\author{
J. A. D. R. N. Appuhamy, ${ }^{* 1}$ B. G. Cassell, ${ }^{*}$ and J. B. Cole $†$ \\ ${ }^{*}$ Department of Dairy Science, Virginia Polytechnic Institute and State University, Blacksburg 24061 \\ †Animal Improvement Programs Laboratory, Agricultural Research Service, USDA, Beltsville, MD 20705-2350
}

\begin{abstract}
The objective of this study was to investigate phenotypic and genetic relationships of common health disorders in dairy cows with milk (PMY) and fat (PFY) yield persistencies. Health and production data from 398 commercial dairy herds were used. Disease traits were defined in binary form for individual lactations considering mastitis only during the first $100 \mathrm{~d}$ in milk (MAST1), only after $100 \mathrm{~d}$ in milk (MAST2), and at any stage of lactation (MAST), and reproductive disorders (REPRO), metabolic disorders (METAB), and lameness (LAME). The persistencies were defined to be uncorrelated with 305-d yields. Impact of the diseases on PMY and PFY were investigated separately in first (FL) and later (LL) lactations. Phenotypic associations of PMY and PFY with likelihood of diseases in current and subsequent lactations were examined using odds ratios from a logistic regression model. Linear-threshold sire-maternal grandsire models were used to estimate genetic correlations of displaced abomasums (DA), ketosis (KET), metritis (MET), MAST, MAST1, and MAST2 with PMY and PFY across parities. Metabolic diseases and REPRO had significantly positive relationships with PMY and PFY in both FL and LL. Significantly greater PMY and PFY were associated with MAST1 in LL. Significantly lower PMY and PFY were related to MAST2 in both FL and LL, whereas cows affected by MAST had significantly less persistent lactations. Incidence of MAST and MAST2 decreased with increasing PMY and PFY in the present and previous lactation. Heritability of disease incidences were 0.03 (DA), 0.01 (KET), 0.10 (MAST), 0.02 to 0.05 (MAST1), 0.02 (MAST2), and 0.04 to 0.10 (MET). Displaced abomasum, KET, MAST, MAST1, and MET had unfavorable genetic correlations of 0.35 , $0.46,0.17,0.02$, and 0.27 with PMY, and 0.16, 0.21, 0.07, 0.06, and 0.12 with PFY, respectively. Favorable
\end{abstract}

Received July 29, 2008.

Accepted November 25, 2008.

${ }^{1}$ Corresponding author: appuhamy@vt.edu genetic correlations were found for MAST2 with PMY $(-0.24)$ and PFY (-0.04). Results suggest that diseases in early lactation increase persistency of milk and fat yield. Selection for greater lactation persistency must consider these antagonistic relationships.

Key words: persistency, disease, genetic correlation, phenotypic correlation

\section{INTRODUCTION}

The antagonistic relationship between high milk production and disease resistance (Simianer et al., 1991) is manifested in increased disease incidence rates in dairy cows (Zwald et al., 2004a). Higher susceptibility to diseases leads to financial loss and has an adverse effect on animal welfare (Jakobsen et al., 2003). Many dairy-producing countries are placing more emphasis on health relative to production in their selection programs (Miglior et al., 2005). However, direct selection of dairy cattle for disease traits is difficult in many countries, including the United States, because data recording practices are not standardized for health traits across farms, and mechanisms for routine retrieval of such data have only recently become available (Zwald et al., 2004b; Cole et al., 2008).

Some investigators have considered indirect selection for disease resistance using correlated traits such as productive life (Rogers et al., 1999) and BCS (Dechow et al., 2004). Jakobsen et al. (2003), Muir et al. (2004), and Harder et al. (2006) suggested that selection for more persistent lactations could be used to reduce the likelihood of health disorders in dairy cows. In addition to anticipated improvement in disease resistance, persistent lactations tend to be more profitable as they incur lower feed costs and generate more return from milk sales when lactations extend beyond $305 \mathrm{~d}$ (Dekkers et al., 1998).

Lack of clear consensus on how best to define persistency is a key issue in genetic evaluation for lactation persistency (Cole and VanRaden, 2006). Many available persistency measures are negatively correlated 
Table 1. Summary statistics for first and later lactations

\begin{tabular}{lccccc}
\hline & \multicolumn{2}{c}{ First lactation } & & \multicolumn{2}{c}{ Later lactations } \\
\cline { 2 - 3 } \cline { 5 - 6 } Variable & Mean & SD & & Mean & SD \\
\hline Milk $^{1}(\mathrm{~kg})$ & 11,738 & 1,974 & & 11,568 & 2,035 \\
Fat $^{2}(\mathrm{~kg})$ & 433 & 84 & & 427 & 88 \\
DIM $^{3}$ & 381 & 110 & & 367 & 95 \\
Days open $_{\text {PMY }}^{4}$ & 166 & 112 & & 166 & 101 \\
PFY $^{5}$ & 0.533 & 1.192 & & 0.430 & 0.922 \\
\hline
\end{tabular}

${ }^{1}$ Total milk yield $(\mathrm{kg})$.

${ }^{2}$ Total fat yield $(\mathrm{kg})$.

${ }^{3}$ Length of lactation (d).

${ }^{4}$ Milk yield persistency of whole lactation.

${ }^{5}$ Fat yield persistency of whole lactation.

with 305-d yield (Dekkers et al., 1998; Jakobsen et al., 2003; Muir et al., 2004), suggesting that selection for higher persistency would occur at the expense of total yield. A persistency measure that is independent of yield will therefore allow more efficient selection for total yield and persistency simultaneously (Muir et al., 2004). Cole and VanRaden (2006) suggested a method to estimate persistency, uncorrelated with yield. We performed a preliminary investigation (Appuhamy et al., 2007) to examine the phenotypic relationship of common health disorders in dairy cows with milk yield persistency estimated using that method. We found positive phenotypic relationships of periparturient disorders such as displaced abomasums (DA), ketosis (KET), and metritis (MET) with persistency of milk yield. Mastitis (MAST) that occurred in late stages of lactation tended to be associated with less persistent lactations. Moreover, that study found a phenotypic correlation of 0.96 between persistencies calculated using daily milk weights and one milk weight per month. This suggested that test-day (TD) milk records can be used to estimate persistency satisfactorily and thereby enhanced the confidence of using TD yields from commercial dairy herds in the genetic evaluation for lactation persistency.

The objective of this study was to investigate the phenotypic and genetic relationships of milk (PMY) and fat (PFY) yield persistencies to common health disorders in Holstein cows using producer-recorded health data and TD yield records.

\section{MATERIALS AND METHODS}

\section{Data}

Persistencies of milk and fat yield for 90,237 Holstein lactations in 405 herds initiated from January 1, 1997, to June 1, 2002, were calculated from TD data obtained from the Animal Improvement Programs Laboratory
(USDA, Beltsville, MD). The health data pertaining to these lactations were provided by Dairy Records Management Systems (DRMS, Raleigh, NC).

Not all lactations in the data included records for all diseases because some diseases were not recorded in some herd-years. Lactations from herd-years having health records for at least 2 diseases were first chosen from the data. The defined minimum and maximum ages for first, second, third, and fourth calvings were 20 to 38,32 to 52,43 to 70 , and 54 to $88 \mathrm{mo}$, respectively. Fifth calvings beginning earlier than 66 mo were deleted from the data. Edited data included 87,555 records [43,232 first (FL) and 44,323 later lactations (LL)] from 398 herds. Summary statistics of the edited data are presented in Table 1.

\section{Defining Disease Traits}

The disease traits MAST, MET, retained placenta (RP), cystic ovaries (CYST), KET, DA, and lameness (LAME) were used because they are common health disorders in dairy cows (Zwald et al., 2004a). Three disease traits pertaining to mastitis: MAST, MAST1, and MAST2 representing at least one mastitis incidence at any stage of lactation, only before 100 DIM, and only after 100 DIM, respectively, were formed. The LAME trait was formed considering treatment incidences for foot rot, hoof abscess, heel warts, laminitis, and other causes of lameness. Health events pertaining to MET, $\mathrm{RP}$, and CYST were pooled to form a single reproductive disease trait (REPRO). Treatment incidences for both KET and DA were considered together to form one metabolic disease trait (METAB). The individual disease traits KET, DA, and MET were used in the calculation of genetic correlations. Each disease trait was defined as a binary variable distinguishing between cows with at least one reported incident during the defined period (1) and cows without cases (0) (Carlen et al., 2004). 
Table 2. Lactation incidence rates for each disease trait in first lactations (FL), later lactations (LL), and across parities (ALL)

\begin{tabular}{|c|c|c|c|c|c|}
\hline \multirow[b]{2}{*}{ Disease trait $^{1}$} & \multirow[b]{2}{*}{ Herds, ${ }^{2} \mathrm{n}$} & \multirow[b]{2}{*}{$L A C_{t}^{3}$} & \multicolumn{3}{|c|}{ Lactation incidence rate ${ }^{4}(\%)$} \\
\hline & & & FL & LL & ALL \\
\hline MAST1 & 260 & 56,115 & 2.7 & 3.0 & 2.9 \\
\hline MAST2 & 260 & 58,118 & 3.9 & 6.0 & 5.0 \\
\hline MAST & 260 & 58,118 & 9.5 & 12.7 & 11.2 \\
\hline LAME & 193 & 43,168 & 13.3 & 17.3 & 15.3 \\
\hline REPRO & 342 & 77,106 & 17.7 & 20.3 & 19.0 \\
\hline KET & 118 & 24,528 & 5.2 & 5.9 & 5.6 \\
\hline DA & 202 & 44,839 & 4.1 & 3.7 & 3.9 \\
\hline METAB & 226 & 49,220 & 6.4 & 7.0 & 6.8 \\
\hline
\end{tabular}

\section{Disease Incidence}

Disease incidence was expressed as lactation incidence rate $(\mathbf{L I R})$ :

$$
L I R=\left(\frac{L A C_{d}}{L A C_{t}}\right) \times 100,
$$

where $L A C_{d}$ is the number of lactations with at least one incidence of the disease and $L A C_{t}$ is the total number of lactations at risk of the disease. Lactations during which the disease of interest was recorded were chosen as $L A C_{t}$ (i.e., 49,220 lactations were from 226 herds that recorded KET, DA, or both). Thus, $L A C_{t}$ of METAB was 49,220 across parities. Similarly, $L A C_{t}$ of MAST, LAME, and REPRO were 58,118 lactations from 260 herds; 43,168 lactations from 193 herds; and 77,106 lactations from 342 herds, respectively (Table 2 ). These data included only the dates of the first disease incidence and a count of incidents (n) in an individual lactation. Lactations in which only one MAST incidence $(\mathrm{n}=1)$ was recorded before 100 DIM were considered as lactations that were affected by MAST1. In determining $L A C_{t}$ of MAST1, lactations that not only had the first MAST record before 100 DIM, but also had multiple incidences $(n>1)$ were deleted as we were unable to recognize the timing (before or after 100 DIM) of the rest of the incidences. Hence, 2,003 lactations were deleted, leaving 56,115 for $L A C_{t}$ of MAST1 (Table 2). Lactations with their first mastitis incident recorded after 100 DIM were considered to be positive for MAST2.

\section{Calculation of Persistency}

Persistency of milk and fat yield were calculated for whole lactation by best prediction (Cole and VanRaden,
2006). According to this method, persistency can be calculated for the whole lactation by multiplying TD yield deviations from a trait-specific standard lactation curve by TD DIM deviations around a trait-specific reference date, $d_{0}$ :

$$
p=\sum_{i=1}^{n}\left(Y_{i}-S_{i}\right) \times\left(d_{i}-d_{0}\right),
$$

where $p=\mathrm{PMY}$ or PFY of an individual lactation; $Y_{i}$ $=i$ th TD milk or fat yield; $S_{i}=$ milk or fat yield from the standard lactation curve on $i$ th TD; $d_{i}=$ DIM at $i$ th TD; $d_{0}=$ reference DIM for milk or fat; and $n=$ total number of TD yield records used to calculate the persistency. Let $\mathbf{t}$ represent the vector whose elements are TD yield deviations $\left(Y_{i}-S_{i}\right)$ and $\mathbf{q}$ represent the vector whose elements are TD DIM deviations $\left(d_{i}-\right.$ $\left.d_{0}\right)$. Then, persistency $\mathbf{p}=\mathbf{q}^{\mathbf{}} \mathbf{t}$. If $\mathbf{d}$ is the vector with elements, $\mathrm{d}_{\mathrm{i}}$, then $\mathbf{q}=\mathbf{d}-\mathbf{1} d_{0}$ and persistency $\boldsymbol{p}=$ $\left(\mathbf{d}^{\prime}-\mathbf{1}^{\prime} d_{0}\right) \mathbf{t}$. The reference date, $d_{0}$, is a constant that makes lactation persistency uncorrelated with total yield. Therefore, $d_{0}$ was obtained by setting Cov (q't, 1't) to 0 and solving for $d_{0}$ :

$$
\begin{gathered}
\operatorname{Cov}\left(\mathbf{q}^{\prime} \mathbf{t}, \mathbf{1}^{\prime} \mathbf{t}\right)=\mathbf{q}^{\prime} \mathbf{V} \mathbf{1}=\left(\mathbf{d}^{\prime}-\mathbf{1}^{\prime} d_{0}\right) \mathbf{V} \mathbf{1}= \\
\mathbf{d}^{\prime} \mathbf{V} \mathbf{1}-\mathbf{1}^{\prime} \mathbf{V} \mathbf{1} d_{0}=0, \\
d_{0}=\mathbf{d}^{\prime} \mathbf{V} \mathbf{1} / \mathbf{1}^{\prime} \mathbf{V} \mathbf{1},
\end{gathered}
$$

where $\mathbf{V}$ is the variance of $\mathbf{t}$ (Cole and VanRaden, 2006).

Trait-specific standard curves were calculated for each breed and parity group within a herd by fitting Wood's curves to herd average yields (Cole and VanRaden, 2007), and 128 and 146 DIM were used as $d_{0}$ for 
milk and fat yields, respectively (Cole and VanRaden, 2006).

Standardized estimates $(\hat{s})$ of PMY and PFY were obtained by subtracting the corresponding within-herd mean $\left(\mu_{p}\right)$ and dividing by the within-herd standard deviation of the persistency $p\left(S D_{p}\right)$ :

$$
\hat{s}=\frac{p-\mu_{p}}{S D_{p}} .
$$

Positive values of $\hat{s}$ indicate increased persistency relative to a cow with average persistency in a herd, and negative values of $\hat{s}$ indicate decreased persistency. Persistencies that exceeded \pm 4.00 were limited to an absolute value of 4 (Cole and VanRaden, 2006). Increased persistency means that more milk was produced after the reference date than was expected based on the standard lactation curve. Decreased persistency indicates less-than-expected yield after the reference date.

\section{Phenotypic Relationships Between Diseases and Persistency}

We examined the phenotypic relationships of the disease traits to persistencies through the effects of the diseases on the persistency and then by the effect of persistency on probabilities of disease occurrence.

Effects of Diseases on PMY and PFY. The following statistical model was used to investigate the impact of each disease trait on persistency:

$$
\begin{aligned}
Y_{i j k l}=\mu & +H Y S_{i}+D_{j}+O_{k}+\beta_{1} D O_{i j k l} \\
& +\beta_{2} A G E_{i j k l}+e_{i j k l},
\end{aligned}
$$

where $Y_{i j k l}=$ standardized PMY or PFY; $\mu=$ overall mean of PMY or PFY; $H Y S_{i}=$ fixed effect of herdyear-season [calving years: 1997, 1998, 1999, 2000, 2001, and 2002, and seasons: 1(January-April), 2 (May-August), and 3 (September-December)]; $D_{j}=$ fixed effect of the main disease of interest $(j=1$ or 0$) ; O_{k}=$ fixed effect of the other diseases $(k=1$ or 0$)$ besides the main disease of interest; $\beta_{1}=$ regression for days open $(\mathbf{D O})$ in lactation $l ; \beta_{2}=$ regression for age at calving (AGE) in mo; and $e_{i j k l}=$ residual error $\sim N\left(0, I \sigma_{e}^{2}\right)$. Effect of interaction between $\mathrm{D}$ and $\mathrm{O}$ was statistically nonsignificant and dropped from the statistical model. Days open $<50$ were set to 50 , and DO $>250$ were set to 250 (Cole and VanRaden, 2006). Separate analyses were performed for FL and LL.

The variable other diseases $(\mathrm{O})$ included respiratory diseases, dystocia, and fever (elevated temperature) as well as the disease traits other than the disease of inter- est in an analysis. Thus, the other diseases for MAST1 were MAST2, REPRO, METAB, LAME, respiratory diseases, dystocia, and fever. The effect of $\mathrm{O}$ was defined as a binary variable distinguishing between lactations with at least one incidence of any other disease (1) and lactations with no incidence of other disease (0).

Effects of PMY and PFY on Disease Incidence. We examined the effect of persistency on likelihood of the diseases in same lactation as well as next lactation through odds ratios and associated confidence intervals (CI) using the following logistic regression model (Appuhamy et al., 2007):

$$
\begin{aligned}
\eta_{i j k .} & =\beta_{0}+H Y S_{i}+O_{j}+\beta_{1} P_{i j k} \\
& +\beta_{2} A G E_{i j k}+\beta_{3} D O_{i j k},
\end{aligned}
$$

where $\eta=$ logit of observing the disease; $\beta_{0}=$ intercept; $H Y S_{i}=$ fixed effect of $i$ th herd-year-season; $O_{j}=$ fixed effect of presence $(j=1)$ or absence $(j=0)$ of any other disease; $\beta_{1}=$ regression for PMY or PFY; $\beta_{2}=$ regression for age (AGE) at calving in months; and $\beta_{3}$ $=$ regression for DO.

An odds ratio can be interpreted as the estimated change in the dependent variable in response to a unit change in an independent variable (Montgomery et al., 2001). An odds ratio of 1.0 is interpreted to mean that there is no association between the dependent variable and the independent variable of interest. The significance of the odds ratio was determined based on its $95 \%$ CI; a CI including 1 indicates a nonsignificant change in the probability of the disease in response to increasing persistency. The effects of persistency on the probabilities of MAST2, MAST, and LAME in the same lactation were examined separately for FL and LL. The same logistic model with addition of DO in the previous lactation was used to investigate the effects of persistency on disease incidence in the next lactation. Data included 9,035 cows from 184 herds for MAST1; 10,184 cows from 186 herd for MAST2 and MAST; 14,500 cows from 253 herds for REPRO; 7,562 cows from 137 herds for LAME; and 8,088 cows from 157 herds that had both first and second lactations.

\section{Genetic Relationships Between Diseases and Persistency}

A bivariate sire-maternal grandsire (S-MGS) linearthreshold model was fit to the data across parities. Disease status was treated as a binary trait and persistency of milk or fat yield as a continuous trait:

$$
\begin{gathered}
\boldsymbol{p}_{i j k l}=H Y_{i}+S_{j}+L A C_{k}+\beta_{1} D I M+e_{i j k l}, \text { and } \\
\lambda_{i j k l}=H Y_{i}+S_{j}+L A C_{k}+\beta_{1} D I M+e_{i j k l},
\end{gathered}
$$


where $\boldsymbol{p}$ is a vector of persistency of yield of daughters; $\boldsymbol{\lambda}$ is a vector of unobserved liabilities to disease; $H Y$ is the random effect of herd-year of calving $i ; S$ is the random effect of sire $j ; L A C$ is the fixed effect of lactation (parity) $k$; DIM is the effect of days in milk; and $e_{i j k l}$ is a random residual effect. Residual variances were 0.85 and 0.79 for persistency of milk and fat, respectively (Cole and VanRaden, 2006), and the health traits were assigned a value of 1 . (Co)variance components were estimated from the data using Bayesian procedures (Sorensen et al., 1995) as implemented in the THRGIBBS1F90 computer program (Tsuruta and Misztal, 2006).

A random herd-year effect was used to avoid the extreme category problem in which all records in a fixed group belong to the same category (Harville and Mee, 1984; Misztal et al., 1989; Luo et al., 2001). This strategy has been successfully used in the United States calving ease system for almost 20 yr (Berger, 1994; Van Tassell et al., 2003).

Prior distributions were flat for the fixed effects and normal for the herd-year and sire effects. Quasi-REML (co)variance components estimated from linear-linear models in which disease incidence was analyzed as a linear trait were used as starting values for the Bayesian analysis (data not shown). For each of the 12 analyses, a single Gibbs chain of 50,000 samples was drawn, the first 10,000 samples were discarded as burn-in, and every fifth sample from the remaining 40,000 samples was included in the summary. Given that only a single threshold was used and that no trend was observed in plots of the Gibbs samples for each of the random effects, a longer burn-in period was not needed. Heritabilities and correlations were calculated from the posterior means of the (co)variance components.

\section{RESULTS AND DISCUSSION}

\section{Persistency Estimates}

Means for PMY and PFY in FL and LL are in Table 1. These means were calculated for the lactations in the edited data. The positive mean values indicate that the edited data included more highly persistent lactations than the standard lactation curves used as reference. The frequency histograms of PMY and PFY appear in Figure 1. The persistency values were rounded to form persistency classes for the histograms (e.g., persistency class 0 included lactations having persistency $<0.5$ and $>-0.5)$. Greater frequencies of the positive persistency classes further indicate that data included more of the highly persistent cows (persistency $>0$ ) than lowly persistent cows (persistency $<0$ ). The mean PMY and PFY were greater in FL than in LL, consistent with the
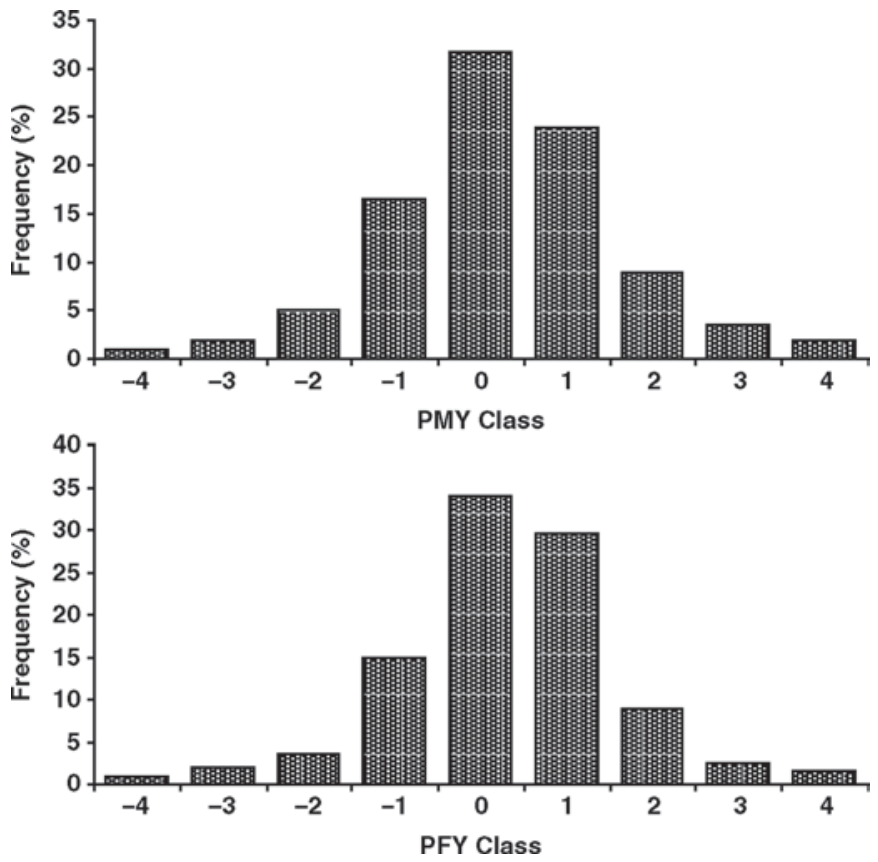

Figure 1. Distribution of milk (PMY) and fat (PFY) yield persistencies; persistency classes were formed by rounding the standardized persistency values across parities to the nearest integer.

consensus that lactation curves of primiparous cows are more persistent than those of multiparous cows.

\section{Disease Incidence}

As shown in Table 2, 342 herds of 398 herds (86\%) recorded REPRO, whereas KET was recorded by only $30 \%$ of the herds in our data. Zwald et al. (2004a) noted that fewer commercial Holstein herds recorded KET and LAME in their data. Difficulties in uniform diagnosis and high variation of the threshold level for veterinary treatment might have restricted the recording of these diseases in commercial herds. Furthermore, Zwald et al. (2004a) and Cole et al. (2008) noted that herd management software might also influence the health data recording in dairy farms. According to these authors, herds that use DairyCOMP 305 (Valley Agricultural Software, Tulare, CA) and PCDART (DRMS) are more likely to record health events.

Table 2 has LIR of the diseases considered in this study. It is difficult to compare disease incidence across different studies because procedures for diagnosis, data recording methods, and disease trait definitions vary from study to study (Harder et al., 2006). However, Zwald et al. (2004a) reported mean LIR for DA, KET, MAST, LAME, and MET (including retained placenta) using some of the same data recording systems as used in this study. Lactation incidence rates for MAST and KET in this study were much smaller (11.2 vs. $20 \%$ for 
Table 3. Frequencies for the first incidence of health disorders by month of lactation (month) across parities

\begin{tabular}{|c|c|c|c|c|c|c|c|c|}
\hline Month & \multicolumn{8}{|c|}{ Trait $^{1}$} \\
\hline 1 & 64.88 & - & 36.47 & 93.92 & 82.65 & 88.3 & 11.61 & 66.54 \\
\hline 3 & 14.19 & - & 8.29 & 0.88 & 1.39 & 1.14 & 10.01 & 6.80 \\
\hline 4 & 6.18 & 12.81 & 8.39 & 0.37 & 1.04 & 0.71 & 11.24 & 5.51 \\
\hline 5 & - & 16.67 & 7.35 & 0.22 & 1.68 & 0.95 & 10.48 & 3.50 \\
\hline 9 & - & 12.06 & 5.32 & 0.29 & 1.50 & 0.90 & 8.47 & 1.21 \\
\hline 10 & - & 12.24 & 5.40 & 0.18 & 2.20 & 1.19 & 9.97 & 1.02 \\
\hline
\end{tabular}

${ }^{1} \mathrm{MAST} 1=$ mastitis in only first $100 \mathrm{~d}$ of lactation; MAST2 = mastitis only after $100 \mathrm{DIM}$; MAST = mastitis in any stage of lactation; KET = ketosis; DA = displaced abomasums; METAB = metabolic disorders; LAME = lameness; and REPRO = reproductive disorders .

MAST and 5.6 vs. $10 \%$ for KET) and that for LAME was greater (15.6 vs. $10 \%)$ compared with results of Zwald et al. (2004a). Those authors obtained health data from DRMS and from Alta Genetics (Watertown, WI) Advantage Progeny Test Program cooperators. Trends of disease frequencies from FL to LL in this study were similar to those of Wilson et al. (2004) and Appuhamy et al. (2007). The disease frequencies of MAST and LAME increased from FL to LL, whereas REPRO and METAB were relatively similar in FL and LL.

The distribution of first incidence of each disorder by months in milk across a 305-d lactation appears in Table 3. As expected, most KET (94\%), DA (83\%), and REPRO (67\%) events occurred during the first 30 d of lactation. Zwald et al. (2004a) observed similar frequencies: $90 \%$ for KETO, $79 \%$ for DA, and $61 \%$ REPRO (excluding cystic ovaries), during the first month of lactation. Using data from university research herds, Appuhamy et al. (2007) reported that more than $85 \%$ of the incidences of KET, DA, and MET occurred during the first $30 \mathrm{~d}$ after calving. About $36 \%$ of MAST incidences occurred in the first month of lactation with the rest of the incidences equally distributed across lactation. Wilson et al. (2004) and Hinrichs et al. (2005) observed a similar pattern of mastitis incidence distribution. Incidences of LAME were evenly distributed throughout the lactation.

\section{Phenotypic Relationships Between Diseases and Persistency in Current Lactation}

First Lactations. Table 4 has the least squares means (LSM) for PMY and PFY with (1) or without $(0)$ each health disorder and the significance ( $P$-value) of the impact of each disorder on the persistencies. Mastitis only in late lactation, MAST, REPRO, and METAB had significant $(P<0.01)$ associations with
PMY and PFY in FL. Primiparous cows that were affected by metabolic diseases such as DA and KET, and reproductive disorders such as RP and MET tended to have more persistent lactations compared with healthy cows. As Table 3 shows, the majority (67\%) of METAB and REPRO incidences occurred during first $30 \mathrm{~d}$ of lactation. Thus, illness in early lactation of primiparous cows leads to more persistent lactations. Appuhamy et al. (2007) made the same observations in research herd data. Muir et al. (2004) and Harder et al. (2006) observed similar relationships with respect to calving difficulty and postpartum metabolic diseases. Appuhamy et al. (2007) further observed a positive phenotypic correlation of 0.70 between PMY and DIM at peak yield. Early lactation diseases may delay peak yield and thereby make the lactations more persistent. Ferris et al. (1985) suggested that delayed peak allows cows to utilize energy slowly and efficiently without experiencing a rapid decline of yield in late lactation. On the other hand, the primiparous cows that developed MAST and MAST2 tended to have significantly lower PMY $(P=0.002$ and $P<0.0001$, respectively $)$ and PFY $(P<0.0001)$.

Odds ratios and associated CI for the effect of persistency on probabilities of diseases in current FL and LL are presented in Table 5. As previously discussed, the majority of MAST1, METAB, and REPRO incidences occurred during first $30 \mathrm{~d}$ of lactation (Table 3 ). The phenotypic expression of these periparturient disease traits was under minimal influence of persistency in the same lactation. Hence, we chose not to include MAST1, METAB, and REPRO in the analyses for the effects of diseases on persistencies in same lactation. Odds ratios $<1$ and CI that do not include zero indicate that both PMY and PFY tended to reduce the likelihood that a cow would develop MAST, particularly MAST2. The disease incidences of MAST and MAST2 in primiparous cows were reduced by 0.12 and 0.21 , respectively, for a 
Table 4. Least squares means (LSM) and associated standard errors, and significance ( $P$-value) for the effect of each disease trait on PMY and PFY in first lactations

\begin{tabular}{|c|c|c|c|c|c|c|}
\hline Disease trait $^{1}$ & \multicolumn{3}{|c|}{$\mathrm{PMY}^{2}$} & \multicolumn{3}{|c|}{$\mathrm{PFY}^{3}$} \\
\hline MAST2 & $0.36 \pm 0.01$ & $0.09 \pm 0.04$ & $<0.0001$ & $0.35 \pm 0.01$ & $0.11 \pm 0.03$ & $<0.0001$ \\
\hline MAST & $0.36 \pm 0.02$ & $0.28 \pm 0.03$ & 0.002 & $0.36 \pm 0.01$ & $0.26 \pm 0.03$ & $<0.0001$ \\
\hline REPRO & $0.29 \pm 0.01$ & $0.46 \pm 0.02$ & $<0.0001$ & $0.31 \pm 0.01$ & $0.40 \pm 0.02$ & $<0.0001$ \\
\hline METAB & $0.37 \pm 0.02$ & $0.96 \pm 0.05$ & $<0.0001$ & $0.34 \pm 0.02$ & $0.74 \pm 0.06$ & $<0.0001$ \\
\hline
\end{tabular}

${ }^{1}$ MAST1 $=$ mastitis in only first $100 \mathrm{~d}$ of lactation; MAST2 = mastitis only after 100 DIM; MAST = mastitis in any stage of lactation; REPRO $=$ reproductive disorders; METAB $=$ metabolic disorders; and LAME $=$ lameness .

${ }^{2}$ Milk yield persistency of whole lactation.

${ }^{3}$ Fat yield persistency of whole lactation.

${ }^{4} \mathrm{LSM}$ of lactations not affected by the disease.

${ }^{5} \mathrm{LSM}$ of lactations affected by at least a single incidence of the disease.

1-SD-unit increase of PMY. Moreover, the corresponding $95 \%$ CI of 0.85 to 0.90 for MAST and 0.75 to 0.83 for MAST2 suggest significant associations of PMY to MAST and MAST2 in primiparous cows.

Later Lactations. Table 6 has the LSM of PMY and PFY in LL that were affected (1) or not affected (0) by each health disorder and the significance ( $P$-value) of the association between each health disorder and persistency measures in multiparous cows. The positive effects of MAST1 that were not significant $(P=0.115$ for PMY and $P=0.0745$ for PFY) in FL were significant $(P<0.0001$ for PMY and $P<0.0022$ for PFY) in LL. A sharp peak followed by a rapid decline in milk yield often characterizes lactation curves of multiparous cows. Conversely, primiparous cows have flatter lactation curves (Stanton et al., 1992). The depressing effect of MAST1 on early lactation yields, leading to a more persistent lactation, appears to be more important in multiparous cows than in primiparous cows.

Mastitis occurring only after 100 DIM was significantly associated with low PMY and PFY in LL, in- dicating that multiparous cows with MAST2 tended to produce less milk in late lactation than uninfected cows. Mastitis may enhance the apoptosis rate of mammary secretory cells, which is solely responsible for the decline in milk yield after peak lactation (Capuco et al., 2001). Therefore, the effect of mastitis on persistency can be negative when it occurs in late lactation. The relationships of MAST to PMY $(P=0.24)$ and PFY $(P=0.35)$ were not significant in multiparous cows. Lactations that were affected by MAST in early, late, or both stages of lactations were considered to be positive for MAST. Therefore, the nonsignificant association between MAST and the persistencies result from counteracting positive effects of MAST1 and negative effects of MAST2 on PMY and PFY. Metabolic disease incidence and REPRO were significantly $(P<0.0001)$ related to greater persistencies in LL as observed for FL. This suggests that both primiparous and multiparous cows that develop periparturient health disorders tend to have more persistent lactations for milk and fat yields. Nonsignificant relationships of LAME to PMY

Table 5. Odds ratios with associated $95 \%$ confidence intervals (CI) and $P$-values for the effect of current lactation persistency on the likelihood of diseases in first and later lactations

\begin{tabular}{|c|c|c|c|c|c|c|c|}
\hline \multirow[b]{2}{*}{ Persistency trait } & \multirow[b]{2}{*}{ Disease trait $^{1}$} & \multicolumn{3}{|c|}{ First lactation } & \multicolumn{3}{|c|}{ Later lactations } \\
\hline & & Odds ratio & CI & $P$-value & Odds ratio & $\mathrm{CI}$ & $P$-value \\
\hline \multirow{2}{*}{$\mathrm{PMY}^{2}$} & MAST2 & 0.79 & $0.75-0.83$ & $<0.0001$ & 0.84 & $0.80-0.88$ & $<0.0001$ \\
\hline & LAME & 0.98 & $0.95-1.02$ & 0.1807 & 1.01 & $0.98-1.05$ & 0.1927 \\
\hline \multirow[t]{2}{*}{$\mathrm{PFY}^{3}$} & MAST & 0.9 & $0.87-0.93$ & 0.0005 & 0.97 & $0.93-1.01$ & 0.4711 \\
\hline & MAST2 & 0.83 & $0.79-0.87$ & $<0.0001$ & 0.91 & $0.87-0.96$ & 0.0002 \\
\hline
\end{tabular}

${ }^{1}$ MAST $=$ mastitis in any stage of lactation; MAST2 $=$ mastitis only after 100 DIM; and LAME = lameness.

${ }^{2}$ Milk yield persistency of whole lactation.

${ }^{3}$ Fat yield persistency of whole lactation. 
Table 6. Least squares means (LSM) and associated standard errors, and significance ( $P$-value) for the effect of each disease trait on PMY and $\mathrm{PFY}$ in later lactations

\begin{tabular}{|c|c|c|c|c|c|c|}
\hline Disease trait ${ }^{1}$ & \multicolumn{3}{|c|}{$\mathrm{PMY}^{2}$} & \multicolumn{3}{|c|}{$\mathrm{PFY}^{3}$} \\
\hline MAST2 & $0.26 \pm 0.01$ & $0.11 \pm 0.02$ & $<0.0001$ & $0.39 \pm 0.03$ & $0.29 \pm 0.04$ & $<0.0001$ \\
\hline MAST & $0.26 \pm 0.02$ & $0.24 \pm 0.03$ & 0.2412 & $0.39 \pm 0.02$ & $0.37 \pm 0.03$ & 0.3520 \\
\hline REPRO & $0.21 \pm 0.02$ & $0.33 \pm 0.02$ & $<0.0001$ & $0.36 \pm 0.01$ & $0.45 \pm 0.02$ & $<0.0001$ \\
\hline METAB & $0.26 \pm 0.06$ & $0.71 \pm 0.07$ & $<0.0001$ & $0.37 \pm 0.06$ & $0.65 \pm 0.08$ & $<0.0001$ \\
\hline
\end{tabular}

${ }^{1}$ MAST1 = mastitis in only first $100 \mathrm{~d}$ of lactation; MAST2 = mastitis only after 100 DIM; MAST = mastitis in any stage of lactation; REPRO $=$ reproductive disorders; METAB $=$ metabolic disorders; and LAME $=$ lameness.

${ }^{2}$ Milk yield persistency of whole lactation.

${ }^{3}$ Fat yield persistency of whole lactation.

${ }^{4} \mathrm{LSM}$ of lactations not affected by the disease.

${ }^{5} \mathrm{LSM}$ of lactations affected by at least a single incidence of the disease.

and PFY in both FL and LL indicate that the effect of locomotive diseases on lactation curve shape is almost negligible.

The odds ratios (Table 5) associated with PMY and PFY in multiparous cows (0.84 and 0.91 for MAST2 and 0.92 and 0.97 for MAST, respectively) were closer to 1.0 than those in primiparous cows. The effect of persistencies on mastitis is weaker in multiparous cows than in primiparous cows. The odds ratios 0.84 for PMY and 0.91 for PFY indicate that the probability of MAST2 in multiparous cows tended to decrease by 16 and $9 \%$ for each SD unit increase in PMY and PFY, respectively. Figure 2 shows that MAST and MAST2 frequencies (estimated across parities) tended to decrease as PMY and PFY increased. Overall, the effect of increasing persistency on MAST2 was greater than that on MAST. Phenotypically, MAST1 is not under the control of persistencies in the same lactation. Hence, the impact of persistency on MAST is similar to the impact of persistency on MAST2.

\section{Phenotypic Associations Between Diseases and Persistency in Previous Lactation}

Table 7 has the odds ratios and CI for the effect of the persistency traits on probability of disease in next lactation. The model included the effect of DO in the previous lactation. Thus, the impact of the persistency in previous lactation on disease incidence was independent of the influence of reproductive status in previous lactation. Higher PMY and PFY tended to reduce the incidence of MAST and MAST2 in the next lactation. An SD unit increase in persistency tended to reduce the probabilities of MAST and MAST in next lactation at least by $10 \%$. The effects of PMY and PFY on disease probabilities were similar, as expected. We found a phenotypic correlation of 0.75 between PMY and PFY.
The odds ratios near 1.0 and associated CI reflect that there were no significant associations among PMY, PFY, and likelihood of METAB and REPRO in next lactation. On the other hand, we observed highly significant $(P<0.0001)$ effects of these periparturient diseases on the persistency measures in both primiparous
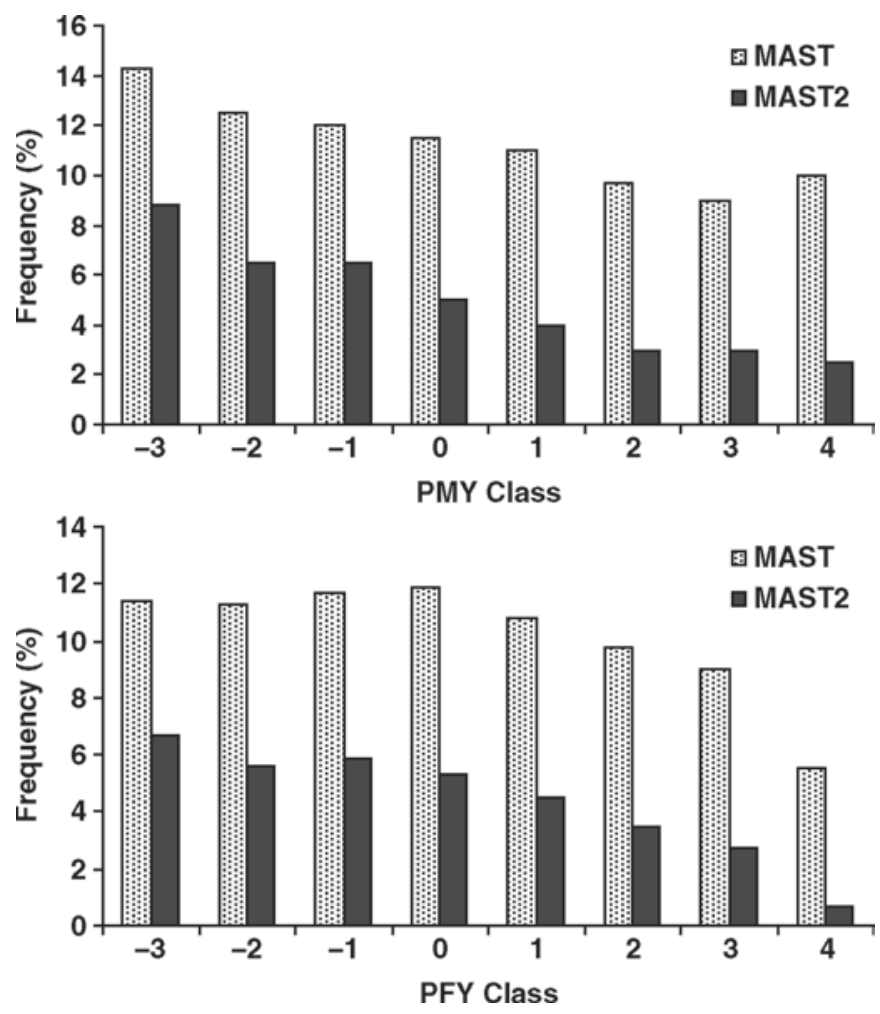

Figure 2. Frequency distribution of mastitis occurring at any point in lactation (MAST) and mastitis occurring only after 100 DIM (MAST2) by persistency of milk (PMY) and fat (PFY) yield classes; persistency classes were formed by rounding the standardized persistency values across parities to the nearest integer. 
Table 7. Odds ratios with associated $95 \%$ confidence intervals (CI) and $P$-values for the effect of the persistency on the likelihood of diseases in next lactation

\begin{tabular}{|c|c|c|c|c|c|c|}
\hline \multirow[b]{2}{*}{ Disease trait $^{1}$} & \multicolumn{3}{|c|}{$\mathrm{PMY}^{2}$} & \multicolumn{3}{|c|}{$\mathrm{PFY}^{3}$} \\
\hline & Odds ratio & CI & $P$-value & Odds ratio & $\mathrm{CI}$ & $P$-value \\
\hline MAST2 & 0.75 & $0.70-0.82$ & $<0.0001$ & 0.83 & $0.76-0.94$ & 0.0003 \\
\hline MAST & 0.86 & $0.82-0.91$ & 0.0002 & 0.90 & $0.85-0.95$ & 0.0013 \\
\hline REPRO & 1.00 & $0.97-1.03$ & 0.9451 & 0.97 & $0.98-1.01$ & 0.1615 \\
\hline METAB & 1.04 & $0.98-1.12$ & 0.1326 & 1.03 & $0.96-1.10$ & 0.2133 \\
\hline
\end{tabular}

${ }^{1}$ MAST1 $=$ mastitis in only first $100 \mathrm{~d}$ of lactation; MAST2 = mastitis only after 100 DIM; MAST = mastitis in any stage of lactation; REPRO $=$ reproductive disorders; METAB $=$ metabolic disorders; and LAME $=$ lameness .

${ }^{2}$ Milk yield persistency of whole lactation.

${ }^{3}$ Fat yield persistency of whole lactation.

and multiparous cows. One general conclusion is that periparturient health disorders in dairy cows tend to significantly affect persistency, whereas disease occurrence is not greatly affected by increasing persistency in the current or previous lactation. Our definition of persistency was independent of total lactation yield. Hence, the effects of diseases investigated in this study were the effects on the shape of the lactation curve rather than on total milk produced. The probability of LAME was not significantly affected by PMY and PFY of either the same lactation or the previous lactation. We made similar observations in the study with research herd data (Appuhamy et al., 2007). Moreover, LAME had no significant impact on the persistencies in either primiparous or multiparous cows. Perhaps lameness was not severe enough to affect daily yields in a meaningful way. We did not choose LAME for the genetic analysis in this study.

\section{Genetic Relationships Between Diseases and Persistency Across Parities}

Bivariate linear-threshold S-MGS models were used to estimate genetic correlations between diseases and lactation persistencies. Besides the genetic correlations, these models produced an estimate of heritability for each health disorder, as presented in Table 8. Similar heritability estimates of $0.03,0.01,0.10$, and 0.02 were obtained from both models for DA, KET, MAST, and MAST2, respectively. However, the 2 models gave different heritability estimates for MAST1 and MET: 0.05 and 0.10 from the model including PMY and 0.02 and 0.04 from the model including PFY, respectively. Harder et al. (2006) used 2 single-trait threshold sire models to estimate genetic correlations between health disorders and lactation persistency in German Holstein cows. They obtained somewhat similar heritability estimates (0.05 to 0.08 ) for udder disorders (95\% of the incidences were MAST) but greater heritability esti- mates (0.04 to 0.12) for METAB. Moreover, Zwald et al. (2004a) obtained quite similar heritability estimates of 0.06 for MET and 0.09 for MAST using a multipletrait threshold model. Their heritability estimates for DA and KET (0.14 and 0.06, respectively) were greater than our results in this study. We obtained small standard deviations for the estimated genetic variations (Table 8) ranging from 0.00005 to 0.007 . It appears that disease traits that could be developed from producerrecorded health data are under some degree of genetic control, and genetic selection based on such data could help reduce the disease incidence among dairy cows.

Estimated genetic correlations of health disorders with PMY and PFY are in Table 9. All health disorders except MAST2 had positive genetic relationships with both PMY and PFY. The 95\% CI were small and did not include zero, suggesting that genetic correlations between the diseases and PMY or PFY were significant $(P<0.05)$. Periparturient metabolic and reproductive disorders (KET, DA, and MET) exhibited the largest positive genetic correlations with $\mathrm{PMY}(0.46,0.35$, and 0.27 , respectively) and $\mathrm{PFY}(0.21,0.16$, and 0.12 , respectively). We observed similar favorable associations of METAB and REPRO with PMY and PFY based on phenotypic relationships. We further observed positive correlations of MAST1 with PMY and PFY. These results reflect that genetic factors involved in development of early lactation diseases tend to be associated with genetic factors leading to a more persistent lactation. We defined persistency independent of total yield. Hence, relationships between diseases and persistency estimates, either genetic or phenotypic, describe relationships between lactation curve shape and incidence of diseases. Animals tending to develop diseases in early lactation also tended to have more persistent lactation curves, regardless of how much or how little milk they produced.

The MAST trait, which includes mastitis at any stage of lactation, showed positive relationships of 0.17 with 
Table 8. Average genetic variation $\left(\sigma_{g}^{2}\right)$, standard deviations (SD) of $\sigma_{g}^{2}$, and heritabilities of disease traits from bivariate models with either PMY or PFY

\begin{tabular}{llccc}
\hline Disease $^{2}$ trait $^{1}$ & Model $^{2}$ & Average $\sigma_{g}^{2}$ & SD of $\sigma_{g}^{2}$ & Heritability \\
\hline DA & PMY & 0.0004 & 0.00009 & 0.03 \\
\multirow{2}{*}{ KET } & PFY & 0.0004 & 0.00009 & 0.03 \\
& PMY & 0.0049 & 0.00340 & 0.01 \\
MAST & PFY & 0.0001 & 0.00005 & 0.01 \\
& PMY & 0.0373 & 0.00704 & 0.10 \\
MAST1 & PFY & 0.0372 & 0.00737 & 0.05 \\
MAST2 & PMY & 0.0176 & 0.00681 & 0.02 \\
\multirow{2}{*}{ MET } & PFY & 0.0003 & 0.00010 & 0.02 \\
& PMY & 0.0003 & 0.00009 & 0.02 \\
& PFY & 0.0003 & 0.00009 & 0.10 \\
\hline
\end{tabular}

${ }^{1} \mathrm{DA}=$ displaced abomasums; KET = ketosis; MAST = mastitis in any stage of lactation; MAST1 = mastitis in only first $100 \mathrm{~d}$ of lactation; MAST2 = mastitis only after $100 \mathrm{DIM}$; and MET = metritis.

${ }^{2} \mathrm{PMY}=$ milk yield persistency of whole lactation; $\mathrm{PFY}=$ fat yield persistency of whole lactation.

PMY. This observation seems in disagreement with the idea that MAST increases apoptosis of mammary epithelial cells, thus leading to a less persistent lactation (Capuco et al., 2003). Harder et al. (2006) also failed to affirm this relationship, reporting that the estimated genetic correlations between udder diseases and persistency measures were close to zero. Nonetheless, Long et al. (2001) demonstrated significantly increased mammary epithelial cell proliferation during Escherichia coliinduced mastitis in addition to the increased expression of apoptotic genes such as Bax and ICE. The balance between cell apoptosis and cell proliferation could prevent significant decreases in milk secretory cell number and thereby, might lead to a persistent lactation curve of animals that develop MAST. However, the negative genetic correlation $(-0.24)$ between MAST2 (late stage of lactation) and PMY suggests that genes associated with development of mastitis in late lactation also reduce milk yield, leading to a less persistent lactation. This study, through both phenotypic and genetic relationships, shows that mastitis before and after peak lactation has opposite impacts on lactation persistency. Furthermore, Zwald et al. (2006) reported that MAST1 is likely to have a low genetic correlation with MAST2. We did not examine this relationship here.
Harder et al. (2006) emphasized that genetic correlations between lactation persistency and diseases have to be judged in light of the definition of persistency. Muir et al. (2004) suggested that persistency measures uncorrelated with total yield could allow for more efficient selection for total lactation yield and persistency simultaneously. This study used persistency measures uncorrelated with total yield. Therefore, all the relationships between diseases and persistency dealt with the shape of lactation curve independent of the level of production. Ferris et al. (1985), Muir et al. (2004), and Appuhamy et al. (2007) all observed relationships between diseases and lactation curve parameters such as peak lactation and DIM at peak. Hence, an investigation that accounts for phenotypic and genetic associations of diseases to these measures would help to better describe the relationships between diseases and persistency.

The persistency measures used in this study seem to be affected by diseases rather than affecting diseases. Genes associated with greater incidence of many diseases tend to increase lactation persistency. Hence, it is doubtful that selection of dairy cattle for greater lactation persistency independent of total yield would lower disease incidence.

Table 9. Genetic correlations $\left(\mathrm{r}_{\mathrm{g}}\right)$ of disease traits with milk (PMY) and fat (PFY) yield persistencies calculated for whole lactation

\begin{tabular}{lccccc}
\hline Disease trait $^{1}$ & $\mathrm{r}_{\mathrm{g}}$ with PMY & \multicolumn{2}{c}{$95 \%$ confidence limits } & $\mathrm{r}_{\mathrm{g}}$ with PFY & $95 \%$ confidence limits \\
\hline DA & 0.35 & 0.35 & 0.34 & 0.16 & 0.15 \\
KET & 0.46 & 0.46 & 0.46 & 0.21 & 0.16 \\
MAST & 0.17 & 0.17 & 0.17 & 0.07 & 0.07 \\
MAST1 & 0.02 & 0.02 & 0.02 & 0.06 & 0.06 \\
MAST2 & -0.24 & 0.23 & 0.24 & 0.08 & 0.07 \\
MET & 0.27 & 0.27 & 0.28 & 0.12 & 0.03 \\
\hline
\end{tabular}

${ }^{1} \mathrm{DA}=$ displaced abomasums; KET = ketosis; MAST = mastitis in any stage of lactation; MAST1 = mastitis in only first $100 \mathrm{~d}$ of lactation; MAST2 = mastitis only after 100 DIM; and MET $=$ metritis. 


\section{ACKNOWLEDGMENTS}

The authors are grateful for financial support and data provided by Animal Improvement Programs Laboratory (USDA, Beltsville, MD) and the genetic analysis software provided by I. Misztal and S. Tsuruta at the University of Georgia (Athens). The cooperation of the breed associations [Ayrshire Breeders' Association (Columbus, OH), American Guernsey Association (Reynoldsville, OH), American Jersey Cattle Association (Reynoldsville, OH), American Milking Shorthorn Society (Beloit, WI), Brown Swiss Cattle Breeders' Association (Beloit, WI), and Holstein Association USA (Brattleboro, VT)] in supplying pedigree data for registered cows and the dairy records processing centers [AgriTech Analytics (Visalia, CA), AgSource Cooperative Services (Verona, WI), Dairy Records Management Systems (Raleigh, NC, and Ames, IA), and DHI Computing Services (Provo, UT)] in supplying pedigree data for grade cows and lactation yield data are acknowledged.

\section{REFERENCES}

Appuhamy, J. A. D. R. N., B. G. Cassell, J. B. Cole, and C. D. Dechow. 2007. Phenotypic relationships of common health disorders in dairy cows to lactation persistency estimated from daily milk weights. J. Dairy Sci. 90:4424-4434.

Berger, P. J. 1994. Genetic prediction for calving ease in the United States: Data, models, and use by the dairy industry. J. Dairy Sci. $77: 1146-1153$.

Capuco, A. V., S. E. Ellis, S. A. Hale, R. A. Edman, X. Zhao, and M. J. Paape. 2003. Lactation persistency, insights from mammary cell proliferation studies. J. Anim. Sci. 81:18-31.

Capuco, V. A., D. L. Wood, R. Baldwin, K. Mcleod, and M. J. Paape. 2001. Mammary cell number, proliferation, and apoptosis during a bovine lactation: Relation to milk production and effect of bST. J. Dairy Sci. 84:2177-2187.

Carlen, E., E. Strandberg, and A. Roth. 2004. Genetic parameters for clinical mastitis, somatic cell score, and production in the first three lactations of Swedish Holstein cows. J. Dairy Sci. 87:30623070 .

Cole, J. B., D. J. Null, and L. R. Bacheller. 2008. A data exchange format and national database for producer-recorded health event data from on-farm management software. J. Dairy Sci. 91(E Suppl. 1):2-3. (Abstr.)

Cole, J. B., and P. M. VanRaden. 2006. Genetic evaluation and best prediction of lactation persistency. J. Dairy Sci. 89:2722-2728.

Cole, J. B., and P. M. VanRaden. 2007. A Manual for Use of BESTPRED: A program for estimation of lactation yield and persistency using best prediction. Available: http://www.aipl. arsusda.gov/software/bestpred/. Accessed Oct. 2, 2008.

Dechow, C. D., G. W. Rogers, L. Klei, T. J. Lawlor, and P. M. VanRaden. 2004. Body condition scores and dairy form evaluations as indicators of days open in US Holsteins. J. Dairy Sci. 87:35343541.

Dekkers, J. C. M., J. H. Ten Haag, and A. Weersink. 1998. Economic aspects of persistency of lactation in dairy cattle. Livest. Prod. Sci. 53:237-252.
Ferris, T. A., I. L. Mao, and C. R. Anderson. 1985. Selection for lactation curve and milk yield in cattle. J. Dairy Sci. 68:14381448 .

Harder, B., J. Bennewitz, D. Hinrichs, and E. Kalm. 2006. Genetic parameters for health traits and their relationship to different persistency traits in German Holstein dairy cattle. J. Dairy Sci. $89: 3202-3212$

Harville, D. A., and R. W. Mee. 1984. A mixed-model procedure for analyzing ordered categorical data. Biometrics 40:393-408.

Hinrichs, D., E. Steamer, W. Junge, and E. Kalm. 2005. Genetic analyses of mastitis data using animal threshold models and genetic correlation with production traits. J. Dairy Sci. 88:2260-2268.

Jakobsen, J. H., R. Rekaya, J. Jensen, D. A. Sorensen, P. Madesen, D. Gianola, L. G. Christensen, and J. Pedersen. 2003. Bayesian estimates of covariance components between lactation curve parameters and disease liability in Danish Holstein cows. J. Dairy Sci. 86:3000-3007.

Luo, M. F., P. J. Boettcher, L. R. Schaeffer, and J. C. M. Dekkers. 2001. Bayesian inference for categorical traits with an application to variance component estimation. J. Dairy Sci. 84:694-704.

Miglior, F., B. L. Muir, and B. J. Van Doormaal. 2005. Selection indices in Holstein cattle of various countries. J. Dairy Sci. 88:1255-1263.

Misztal, I., D. Gianola, and J. L. Folley. 1989. Computing aspects of nonlinear methods of sire evaluation for categorical data. J. Dairy Sci. 72:1557-1568.

Montgomery, D. C., E. A. Peck, and G. G. Vining. 2001. Introduction to Linear Regression Analysis. 3rd ed. John Wiley \& Sons Inc., New York, NY.

Muir, B. L., J. Fatehi, and L. R. Schaeffer. 2004. Genetic relationships between persistency and reproductive performances in firstlactation Canadian Holsteins. J. Dairy Sci. 87:3029-3037.

Rogers, G. W., G. Banos, and U. Sander-Nielsen. 1999. Genetic correlations among protein yield, productive life and type traits from the United States and diseases other than mastitis from Denmark and Sweden. J. Dairy Sci. 82:1331-1338.

Simianer, H., H. Solbu, and L. R. Schaeffer. 1991. Estimated genetic correlations between diseases and yield traits in dairy cattle. J. Dairy Sci. 74:4358-4365.

Sorensen, D., S. Andersen, D. Gianola, and I. Korsgaard. 1995. Bayesian inference in threshold models using Gibbs sampling. Genet. Sel. Evol. 27:229-249.

Stanton, T. L., L. R. Jones, R. W. Everett, and S. D. Kachman. 1992. Estimating milk, fat, and protein lactation curves with a test day model. J. Dairy Sci. 75:1691-1700.

Tsuruta, S., and I. Misztal. 2006. THRGIBBS1F90 for estimation of variance components with threshold-linear models. Commun. 27-31 in Proc. 8th World Congr. Genet. Appl. Livest. Prod., Belo Horizonte, Brazil.

Van Tassell, C. P., G. R. Wiggans, and I. Misztal. 2003. Implementation of a sire-maternal grandsire model for evaluation of calving ease in the United States. J. Dairy Sci. 86:3366-3373.

Wilson, D. J., R. N. Gonzalez, J. Hertl, H. F. Schulte, G. J. Bennett, Y. H. Schukken, and Y. T. Grohn. 2004. Effect of clinical mastitis on the lactation curve: A mixed model estimation using daily milk weights. J. Dairy Sci. 87:2073-2084.

Zwald, N. R., K. A. Weigel, Y. M. Chang, R. D. Welper, and J. S. Clay. 2004a. Genetic selection for health traits using producer recorded data. I. Incidence rates, heritability estimates, and sire breeding values. J. Dairy Sci. 87:4287-4294.

Zwald, N. R., K. A. Weigel, Y. M. Chang, R. D. Welper, and J. S. Clay. 2004b. Genetic selection for health traits using producerrecorded data. II. Genetic correlations, disease probabilities, and relationships with existing traits. J. Dairy Sci. 87:4295-4302.

Zwald, N. R., K. A. Weigel, Y. M. Chang, R. D. Welper, and J. S. Clay. 2006. Genetic analysis of clinical mastitis data from onfarm management software using threshold models. J. Dairy Sci. 89:330-336. 